\section{JTI}

JOURNAL OF

TRAUMA AND INJURY

\title{
Management of Traumatic Pancreatic Injuries: Evaluation of 7 Years of Ex- perience at a Single Regional Trauma Center
}

\author{
Min A Lee, M.D., Seung Hwan Lee, M.D., Kang Kook Choi, M.D., \\ Youngeun Park, M.D., Gil Jae Lee, M.D., Ph.D., Byungchul Yu, M.D. \\ Department of Trauma Surgery, Gachon University Gil Medical Center, Incheon, Korea
}

Received: August 28, 2021

Revised: September 21, 2021

Accepted: September 23, 2021

\section{Correspondence to}

Byungchul Yu, M.D.

Department of Trauma Surgery, Gachon University Gil Medical Center, 21 Namdong-daero 774beon-gil, Namdong-gu, Incheon 21565, Korea

Tel: +82-32-460-3010

Fax: $+82-32-460-3247$

E-mail: kane2123@gilhospital.com ORCID: https://orcid.org/0000-00022444-2343

Purpose: Traumatic pancreatic injuries are rare, but their diagnosis and management are challenging. The aim of this study was to evaluate and report our experiences with the management of pancreatic injuries.

Methods: We identified all adult patients (age $>15$ ) with pancreatic injuries from our trauma registry over a 7-year period. Data related to patients' demographics, diagnoses, operative information, complications, and hospital course were abstracted from the registry and medical records.

Results: A total of 45 patients were evaluated. Most patients had blunt trauma (89\%) and 21 patients (47\%) had pancreatic injuries of grade 3 or higher. Twenty-eight patients (62\%) underwent laparotomy and 17 (38\%) received nonoperative management (NOM). The overall in-hospital mortality rate was $24 \%(\mathrm{n}=11)$, and only one patient died after NOM (due to a severe traumatic brain injury). Twenty-two patients (79\%) underwent emergency laparotomy and six (21\%) underwent delayed laparotomy. A drainage procedure was performed in 12 patients (43\%), and pancreatectomy was performed in 16 patients (57\%) (distal pancreatectomy [DP], $\mathrm{n}=8$; DP with spleen preservation, $\mathrm{n}=5$; pancreaticoduodenectomy, $\mathrm{n}=2$; total pancreatectomy, $\mathrm{n}=1)$. Fourteen $(31 \%)$ pancreas-specific complications occurred, and all complications were successfully managed without surgery. Solid organ injuries $(n=14)$ were the most common type of associated abdominal injury (Abbreviated Injury Scale $\geq 3$ ).

Conclusions: For traumatic pancreatic injuries, an appropriate treatment method should be considered after evaluation of the accompanying injury and the patient's hemodynamic status. NOM can be performed without mortality in appropriately selected cases.

Keywords: Wounds and injuries; Pancreas

This is an Open Access article distributed under the terms of the Creative Commons Attribution Non-Commercial License (http://creativecommons.org/licenses/by-nc/4.0/) which permits unrestricted noncommercial use, distribution, and reproduction in any medium, provided the original work is properly cited. 


\section{INTRODUCTION}

Traumatic pancreatic injuries are rare, accounting for fewer than $1 \%$ of all trauma patients and $3-12 \%$ of abdominal trauma patients [1-4]. The pancreas is located in the retroperitoneum and is surrounded by important organs. Therefore, pancreatic injuries are often accompanied by injuries of the surrounding organs. These factors delay the diagnosis of pancreatic injuries and make them difficult to manage. For these reasons, pancreatic injuries have high morbidity and mortality rates $[5,6]$.

The treatment of these pancreatic injuries requires a multidisciplinary approach and tends to use a variety of methods, including endoscopy and interventions, with both non-surgical and surgical treatment as deemed appropriate [7]. The aim of this study was to evaluate and report our experiences with the management of pancreatic injuries.

\section{METHODS}

This study surveyed patients who presented to a single regional trauma center for trauma from January 2014 to December 2020. We excluded patients younger than 16 years of age. Data related to patients' demographic characteristics and mechanism of injury were abstracted from the Korea Trauma Database. Patients' medical records were retrospectively reviewed and the following data were evaluated: initial vital signs, laboratory findings, grade of the pancreatic injury, Injury Severity Score (ISS), type of management, and hospital course. The grade of pancreatic injury was classified using the American Association for the Surgery for Trauma (AAST) system.

Quantitative variables were expressed as mean \pm standard deviation. A univariate analysis was performed using the Student $t$-test for continuous variables and the chisquare test for categorical variables. The threshold for statistical significance was set at $p<0.05$. All statistical analyses were performed using SPSS version 20.0 (IBM Corp., Armonk, NY, USA).

\section{RESULTS}

In total, 45 patients were evaluated. Twenty-eight patients (62.2\%) underwent laparotomy and 17 (37.8\%) received nonoperative management (NOM). The demographic and clinical characteristics of the two groups were compared. Most of the patients had blunt injuries (88.9\%) and were injured in a motor vehicle crash $(57.8 \%)$. According to the AAST grading system, 21 patients (46.6\%) had pancreatic injuries of grade 3 or higher. The NOM group contained patients with grade 1-3 injuries, and no patients with grade 4, 5 injuries received NOM. Correspondingly, no grade 1 patients received operative management. The patients who received operative management had poorer Glasgow Coma Scale scores, initial hemoglobin levels, and ISS, and their mortality was high. The overall mortality rate was $24.4 \%(\mathrm{n}=11)$ and only one patient died after NOM, due to a severe traumatic brain injury (Table 1).

Injuries associated with the abdomen (Abbreviated Injury Scale $\geq 3$ ) were present in $93 \%$ of cases, with the highest frequency found for solid organ, hollow viscus, and vascular injuries. A combined injury was defined as having two or more abdominal injuries. Vascular injuries were significantly more common in patients who died than in survivors $(p=0.003)$ (Table 2).

The treatment process of surgical patients was investigated. Twenty-two of the surgical patients underwent emergency surgery and six underwent delayed surgery. Damage control surgery was performed in 14 of the patients who underwent emergency surgery. A drainage procedure was performed in 12 patients $(42.9 \%)$, and pancreatectomy was performed in 16 patients $(57.1 \%)$ : distal pancreatectomy (DP), $\mathrm{n}=8$; DP with spleen preservation, $\mathrm{n}=5$; pancreaticoduodenectomy, $\mathrm{n}=2$; and total pancreatectomy, $n=1$. There were four patients with grade 4 and the following surgeries were performed: drainage procedure, $n=2$; DP with spleen preservation, $n=1$; pancreaticoduodenectomy, $\mathrm{n}=1$. Three of these patients died from disseminated intravascular coagulation due to damage to the organs surrounding the pancreas. One patient who underwent DP survived. There were two patients with AAST grade 5. They underwent pancreaticoduodenectomy and total pancreatectomy but both died. Two 
Table 1. Demographic and clinical characteristics of the analyzed patients

\begin{tabular}{|c|c|c|c|c|}
\hline & Total $(n=45)$ & $\operatorname{NOM}(n=17)$ & Operation $(n=28)$ & $p$-value \\
\hline Age (year) & $47.8 \pm 16.6$ & $48.9 \pm 17.8$ & $47.1 \pm 16.1$ & 0.73 \\
\hline Male & $33(73.3)$ & $13(71.4)$ & $20(76.5)$ & 0.50 \\
\hline Blunt injury & $40(88.9)$ & $17(100.0)$ & $21(82.1)$ & 0.08 \\
\hline \multicolumn{5}{|l|}{ Mechanism } \\
\hline MVC & $26(57.8)$ & $11(64.7)$ & $15(53.6)$ & \\
\hline Motorbike & $5(11.1)$ & $3(17.6)$ & $2(7.1)$ & \\
\hline Fall from height & $4(8.9)$ & $1(5.9)$ & $3(10.7)$ & \\
\hline Stabbing & $5(11.1)$ & $0(0.0)$ & $5(17.9)$ & \\
\hline Others & $5(11.1)$ & $2(11.8)$ & $3(10.7)$ & \\
\hline SBP (mmHg) & $98.9 \pm 47.7$ & $119.4 \pm 39.0$ & $86.5 \pm 48.7$ & 0.17 \\
\hline PR (rate/min) & $87.8 \pm 33.1$ & $83.9 \pm 17.9$ & $90.2 \pm 39.7$ & 0.54 \\
\hline GCS & $12.4 \pm 4.5$ & $14.4 \pm 2.7$ & $11.2 \pm 5.0$ & 0.02 \\
\hline $\mathrm{Hb}(\mathrm{g} / \mathrm{dL})$ & $12.4 \pm 2.8$ & $13.5 \pm 2.3$ & $11.7 \pm 2.8$ & 0.03 \\
\hline ISS & $22.8 \pm 11.4$ & $17.1 \pm 11.0$ & $26.3 \pm 10.3$ & $<0.01$ \\
\hline \multicolumn{5}{|l|}{ AAST grade } \\
\hline Grade 1 & $4(8.9)$ & $4(23.5)$ & $0(0.0)$ & \\
\hline Grade 2 & $19(42.2)$ & $9(52.9)$ & $10(37.0)$ & \\
\hline Grade 3 & $15(33.3)$ & $4(23.5)$ & $11(40.7)$ & \\
\hline Grade 4 & $4(8.9)$ & $0(0.0)$ & $4(14.8)$ & \\
\hline Grade 5 & $2(4.4)$ & $0(0.0)$ & $2(7.4)$ & \\
\hline ICU stay (days) & $6.5 \pm 7.9$ & $3.5 \pm 5.6$ & $8.4 \pm 8.7$ & 0.47 \\
\hline Hospital stay (days) & $31.7 \pm 40.0$ & $33.0 \pm 42.7$ & $30.9 \pm 39.1$ & 0.87 \\
\hline Death & $11(24.4)$ & $1(5.9)$ & $10(35.7)$ & 0.03 \\
\hline
\end{tabular}

Values are presented as mean \pm standard deviation or number (\%).

NOM: nonoperative management, MVC: motor vehicle crash, SBP: systolic blood pressure, PR: pulse rate, GCS: Glasgow Coma Scale, Hb: hemoglobin, ISS: Injury Severity Score, AAST: American Association for the Surgery for Trauma, ICU: intensive care units.

Table 2. Distribution of accompanying abdominal injuries (Abbreviated Injury Scale $\geq 3$ )

\begin{tabular}{|lccc|}
\hline & Survival $(\mathbf{n}=\mathbf{3 4})$ & Death $(\mathbf{n}=\mathbf{1 1})$ & $\boldsymbol{p}$-value \\
\hline None & 14 & $0(0.0)$ & \\
Solid & $12(66.7)$ & $6(33.3)$ & 0.21 \\
Hollow & $7(70.7)$ & $3(30.3)$ & 0.46 \\
Vascular & $2(22.2)$ & $7(77.8)$ & $<0.01$ \\
Combined & $3(37.5)$ & $5(62.5)$ & 0.01 \\
\hline
\end{tabular}

Values are presented as number (\%). patients died after surgery due to necrotizing pancreatitis and anastomosis leakage, respectively.

Complications occurred in nine cases. There were five cases of fluid collection, two cases of pancreatic fistula, one case of anastomosis leakage, and one case of necrotizing pancreatitis (Table 3).

Of the 17 patients who received NOM, 12 were observed without any other procedure. Five patients underwent endoscopic retrograde cholangiopancreatography (ERCP), three of whom underwent pancreatic duct stent insertion. One patient who underwent ERCP was grade 2 and the other four were grade 3. In the NOM patients, five complications occurred, including four pancreatic 
Table 3. Operation type, surgical procedure, and complications

\begin{tabular}{|lcc|}
\hline & Total $(\mathbf{n}=\mathbf{2 8})$ & Death $(\mathbf{n}=\mathbf{1 0})$ \\
\hline Operation type & $22(78.6)$ & $9(40.9)$ \\
Emergency surgery & $14(50.0)$ & $9(64.3)$ \\
Damage control surgery & $6(21.4)$ & $1(16.7)$ \\
Elective surgery & & \\
Surgical procedure & $12(42.9)$ & $4(33.3)$ \\
Drainage and bleeding control & $10(35.7)$ & $3(33.3)$ \\
DP & $3(10.7)$ & $0(0.0)$ \\
Spleen-preserving DP & $2(7.1)$ & $2(100.0)$ \\
Pancreaticoduodenectomy & $1(3.6)$ & $1(100.0)$ \\
Total pancreatectomy & & \\
Complications & $5(17.9)$ & $0(0.0)$ \\
Fluid collection & $2(7.1)$ & $0(0.0)$ \\
Pancreatic fistula & $1(3.6)$ & $1(100.0)$ \\
Anastomosis leakage & $1(3.6)$ & $1(100.0)$ \\
Necrotizing pancreatitis & &
\end{tabular}

Values are presented as number (\%).

DP: distal pancreatectomy.

pseudocysts and one case of pancreatitis (Table 4).

\section{DISCUSSION}

Pancreatic injuries are uncommon, but can be fatal. Although a treatment protocol for pancreatic injuries has been established to some extent, accompanying injuries are common, and the appropriate treatment therefore varies considerably from case to case.

In this study, most injuries resulted from blunt trauma, and traffic accidents were the most common cause. This is similar to the results of previous studies in Korea, Europe, and Australia [8-10]. In contrast, the United States and South Africa have a high rate of penetrating wounds $[1,11,12]$.

The management of pancreatic injuries has not been established with certainty. In most cases, NOM is attempted for low-grade injuries with intact ducts. However, no consensus yet exists regarding the treatment strategy for severe injuries (AAST grades 4, 5). In recent years, there
Table 4. Nonoperative management strategies and complications

\begin{tabular}{|lc|}
\hline & Value $(\mathbf{n}=\mathbf{1 7})$ \\
\hline Endoscopic procedure & $12(70.6)$ \\
None & $5(29.4)$ \\
ERCP & $3(17.6)$ \\
Stent & \\
Complications & $4(23.5)$ \\
Pseudocyst & $1(5.9)$ \\
Pancreatitis & \\
\hline
\end{tabular}

Values are presented as number (\%).

ERCP: endoscopic retrograde cholangiopancreatography.

have been many cases of successful NOM involving embolization or endoscopic procedures, as well as surgical treatment [13].

At our center, 28 patients underwent surgery. The patients who underwent surgery had significantly lower initial $\mathrm{Hb}$ levels, lower GCS scores, and higher ISS. The AAST grade of their injuries was 2 or higher. Since most of the injuries were caused by blunt trauma, there were many accompanying injuries to surrounding organs. For AAST grade 2 injuries, bleeding control and drainage were most commonly performed (in one case, vessel reconstruction was performed with distal pancreatectomy due to multiple lacerations of the proximal superior mesenteric vein), and distal pancreatectomy was performed for AAST grade 3 cases. Two of the patients who underwent distal pancreatectomy had complications and underwent ERCP.

According to Jurkovich [14], the most difficult injuries to manage- and those for which the least consensus exists—are AAST grade 4, 5 injuries. In this study, surgery was performed for all AAST grade 4, 5 injuries. Five patients died after surgery due to disseminated intravascular coagulation, necrotizing pancreatitis and anastomosis leakage.

Six patients underwent delayed surgery due to misdiagnosis. In blunt abdominal injuries, the affected area is extensive and there are often accompanying injuries; therefore, symptoms due to pancreatic injuries appear late. The pancreas is located in the retroperitoneum, and the symptoms felt by the patient are ambiguous and eas- 
ily underestimated by medical staff $[15,16]$. Computed tomography (CT) has recently become the standard imaging technique for diagnosing trauma patients, but in some cases, pancreatic damage cannot be detected on the initial CT scan $[17,18]$. A delayed diagnosis can lead to serious complications such as intra-abdominal bleeding and pancreatic fistula, which can even progress to death [19]. If pancreatic damage is suspected due to the injury mechanism or if unspecified symptoms persist, a secondary CT scan can be performed within 8 to 12 hours to detect pancreatic transection and peripancreatic fluid [14].

NOM was performed in 17 patients, who had relatively low AAST grades (grades 1, 2, and 3). Four patients had pancreatic duct injury (AAST grades 3 ), and all of them underwent ERCP. Among them, three patients were treated with stent insertion. In patients with pancreatic duct injury, successful NOM was achieved by combining ERCP, endoscopic retrograde pancreatic drainage, and percutaneous drainage. There is an increasing trend towards NOM for lower-grade injuries [20]. A recent US study reported that from 1998 to 2009, the proportion of non-surgically managed patients increased from $56.7 \%$ to $59.1 \%(p<0.01)$ and the mortality rate decreased from 9.7\% to $8.6 \%(p<0.0001)$ [13]. The purpose of ERCP is to confirm the diagnosis of pancreatic duct injury and to place a bridge prosthesis in the area of damage [21]. Rogers et al. [4] showed promising results for endoscopic papillary pancreatic duct stenting, but concerns about long-term ductal structure remain.

Fourteen $(31 \%)$ pancreas-specific complications occurred. Among them, two patients with anastomosis leakage and necrotizing pancreatitis, respectively, died. The complications of the remaining patients were managed without surgery. According to the literature, complications of pancreatic injuries are reported to occur in $12-34 \%$ of cases, including abscesses (6-32\%), fistula (10-32\%), pancreatic pseudocyst (5-30\%), and pancreatitis (10-15\%) [22,23].

The mortality rate was $24.4 \%: 35.7 \%$ in the operation group and $5.9 \%$ in the NOM group. The only cause of death in the NOM group was severe traumatic brain injury. According to the literature, the mortality rate of pancreatic injuries is high, with reported rates ranging from as low as $7.1 \%$ to $46.0 \%$. Age, male sex, blunt trauma, he- modynamic compromise, high-grade injuries, and associated vascular injuries have been identified as significant prognostic factors associated with mortality $[2,9,10,24]$.

There are some limitations of this study. First, it was a single-center study that included a small number of patients. Since a randomized controlled study was impossible due to the characteristics of trauma patients, a retrospective study was conducted. Patients with pancreatic injuries are usually polytrauma patients. Therefore, mortality involves various factors.

\section{CONCLUSION}

For traumatic pancreatic injuries, an appropriate treatment method should be considered after evaluation of the accompanying injury and the patient's hemodynamic status. Patients with severe pancreatic injuries requiring surgery have a high mortality rate. NOM can be performed without mortality in appropriately selected cases.

\section{REFERENCES}

1. Chinnery GE, Krige JE, Kotze UK, Navsaria P, Nicol A. Surgical management and outcome of civilian gunshot injuries to the pancreas. Br J Surg 2012;99(Suppl 1):140-8.

2. Kao LS, Bulger EM, Parks DL, Byrd GF, Jurkovich GJ. Predictors of morbidity after traumatic pancreatic injury. J Trauma 2003;55:898-905.

3. Lin BC, Chen RJ, Fang JF, Hsu YP, Kao YC, Kao JL. Management of blunt major pancreatic injury. J Trauma 2004;56:774-8.

4. Rogers SJ, Cello JP, Schecter WP. Endoscopic retrograde cholangiopancreatography in patients with pancreatic trauma. J Trauma 2010;68:538-44.

5. Addison P, Iurcotta T, Amodu LI, Crandall G, Akerman M, Galvin D, et al. Outcomes following operative vs. non-operative management of blunt traumatic pancreatic injuries: a retrospective multi-institutional study. Burns Trauma 2016;4:39.

6. Kaman L, Iqbal J, Pall M, Bhukal I, Behera A, Singh G, et al. Current management of pancreatic trauma. Trop Gastroenterol 2012;33:200-6.

7. Coccolini F, Kobayashi L, Kluger Y, Moore EE, Ansaloni L, Biffl W, et al. Duodeno-pancreatic and extrahepatic biliary tree trau- 
ma: WSES-AAST guidelines. World J Emerg Surg 2019;14:56.

8. Fleming WR, Collier NA, Banting SW. Pancreatic trauma: Universities of Melbourne HPB group. Aust N Z J Surg 1999;69:357-62.

9. Scollay JM, Yip VS, Garden OJ, Parks RW. A population-based study of pancreatic trauma in Scotland. World J Surg 2006;30: 2136-41.

10. Thomas H, Madanur M, Bartlett A, Marangoni G, Heaton N, Rela M. Pancreatic trauma--12-year experience from a tertiary center. Pancreas 2009;38:113-6.

11. Rickard MJ, Brohi K, Bautz PC. Pancreatic and duodenal injuries: keep it simple. ANZ J Surg 2005;75:581-6.

12. Sharpe JP, Magnotti LJ, Weinberg JA, Zarzaur BL, Stickley SM, Scott SE, et al. Impact of a defined management algorithm on outcome after traumatic pancreatic injury. J Trauma Acute Care Surg 2012;72:100-5.

13. Ragulin-Coyne E, Witkowski ER, Chau Z, Wemple D, Ng SC, Santry HP, et al. National trends in pancreaticoduodenal trauma: interventions and outcomes. HPB (Oxford) 2014;16:275-81.

14. Jurkovich GJ. Pancreatic trauma. J Trauma Acute Care Surg 2020;88:19-24.

15. Boffard KD, Brooks AJ. Pancreatic trauma--injuries to the pancreas and pancreatic duct. Eur J Surg 2000;166:4-12.

16. Subramanian A, Dente CJ, Feliciano DV. The management of pancreatic trauma in the modern era. Surg Clin North Am 2007;87:1515-32.
17. Ragozzino A, Manfredi R, Scaglione M, De Ritis R, Romano S, Rotondo A. The use of MRCP in the detection of pancreatic injuries after blunt trauma. Emerg Radiol 2003;10:14-8.

18. Rosenfeld EH, Vogel AM, Klinkner DB, Escobar M, Gaines B, Russell R, et al. The utility of ERCP in pediatric pancreatic trauma. J Pediatr Surg 2018;53:146-51.

19. Biffl WL, Moore EE, Croce M, Davis JW, Coimbra R, KarmyJones R, et al. Western Trauma Association critical decisions in trauma: management of pancreatic injuries. J Trauma Acute Care Surg 2013;75:941-6.

20. Duchesne JC, Schmieg R, Islam S, Olivier J, McSwain N. Selective nonoperative management of low-grade blunt pancreatic injury: are we there yet? J Trauma 2008;65:49-53.

21. Telford JJ, Farrell JJ, Saltzman JR, Shields SJ, Banks PA, Lichtenstein DR, et al. Pancreatic stent placement for duct disruption. Gastrointest Endosc 2002;56:18-24.

22. Vasquez JC, Coimbra R, Hoyt DB, Fortlage D. Management of penetrating pancreatic trauma: an 11-year experience of a level-1 trauma center. Injury 2001;32:753-9.

23. Wolf A, Bernhardt J, Patrzyk M, Heidecke CD. The value of endoscopic diagnosis and the treatment of pancreas injuries following blunt abdominal trauma. Surg Endosc 2005;19:665-9.

24. Akhrass R, Yaffe MB, Brandt CP, Reigle M, Fallon WF Jr, Malangoni MA. Pancreatic trauma: a ten-year multi-institutional experience. Am Surg 1997;63:598-604. 